\title{
Application of dilatometry with modulated temperature for thermomechanical analysis of anti-wear coating/substrate systems
}

\author{
Piotr Myśliński • Lukasz Szparaga • \\ Paweł Kamasa $\cdot$ Adam Gilewicz $\cdot$ Jerzy Ratajski
}

Received: 10 October 2014/Accepted: 7 February 2015/Published online: 4 March 2015

(c) The Author(s) 2015. This article is published with open access at Springerlink.com

\begin{abstract}
Modern vacuum-plasma surface modification technologies of tools for metal and wood machining are based inter alia on the deposition of thin gradient and multilayer protection coatings with a thickness of several micrometers. Exploitation of tools are frequently carried out in complex tribological nodes, where next to mechanical loads, there are significant changes in temperature at the interface of the tool/workpiece material; hence, the knowledge of the thermomechanical stability of the coatings operating under these conditions is an important criterion used in the processes of designing of wear-resistant coating technology. In this paper, the objects of research were three types of gradient PVD coating/molybdenum substrate systems, for which time courses of amplitudes of elongation and equivalent thermal expansion coefficients of the systems were measured. Experimental measurements were made using a temperature-modulated dilatometry using concepts of dynamic load thermomechanical analysis. It was demonstrated that the developed method allows a quantitative determination of the influence of the gradient layer type on the total elongation of the substrate of the system. It was also shown that the changes of thermomechanical properties of the systems during annealing process are correlated with the time evolution of the equivalent
\end{abstract}

P. Myśliński · Ł. Szparaga (凹) · A. Gilewicz · J. Ratajski Faculty of Technology and Education, Koszalin University of Technology, Koszalin, Poland

e-mail: lukasz.szparaga@tu.koszalin.pl

P. Myśliński

e-mail: piotr.myslinski@tu.koszalin.pl

P. Kamasa

Wigner Research Centre for Physics, Research Institute for Solid State Physics and Optics, Hungarian Academy of Sciences, Budapest, Hungary thermal expansion coefficient. In addition, using the concepts of transition function describing the continuous change of physical and chemical parameters as a function of the spatial variables and finite element method for each of the systems, the distributions of internal thermal stresses were determined.

Keywords Dilatometry with temperature modulation . Gradient coatings · Internal stress · Anti-wear PVD coatings

\section{Introduction}

Currently observed intensive development of physical vapor deposition (PVD) coatings that are deposited on the working surfaces of the parts of machines and cutting tools is due to the increasing performance requirements. Very important element in the selection of the process technological parameters of the anti-wear coatings designed [1-6] is the anticipatory knowledge of the thermal stability of coatings. As a result of complex thermomechanical loads that follow from the use process of machine and tool parts, in the protective coatings, there occurs a thermal activation of a number of micro- and macro-scopic processes. These include above all relaxations of stresses, a diffusion process that cause, among others, a growth of the coating material grains, as well as a chemical and mechanical degradation of the coating structures [7-12].

From among anti-wear coatings, the so-called gradient coatings deserve particular attention. They are found in the group of functionally graded materials (FGM), which are characterized by continuous changes of the physico-chemical parameters in the function of spatial variables. The use of gradient coatings makes a reduction possible of 
stresses on layer/substrate boundaries and between the layers of a multi-layered coating. This leads to an improvement of the mechanical properties of coatings, including an increased adhesion of the coating to the substrate as well as an increase in cohesive forces in the individual layers of the coating. A mathematical description of FGM is based on the so-called transition functions that describe a constant change of material parameters such as the Young modulus, the Poisson's ratio, the thermal expansion coefficient or density in the function of spatial variables [13-17]. For the purpose of computer designing and testing of the properties of coatings, simulation packages are used. They are based on the finite element method (FEM), and they make it possible to determine the state of internal stresses and strains in substrate/coating systems, which occur as a result of external thermomechanical loads [18-25]. This offers a possibility to conduct virtual in-service tests that support the selection of the optimal physico-chemical parameters and the geometry of anti-wear coatings [26-28]. Nevertheless, laboratory diagnostic methods of substrate/gradient coating systems need to be developed, ones which are used for an identification of tests of thermally activated macro- and microscopic processes. One of such methods may be the method presented herein; it is based on dilatometry with temperature modulation [1-4]. In the method developed, during isothermic annealation or in the linear temperature change of the substrate-PVD coating system, thermal effects on the coating are represented, ones which occur in the real operational conditions. From the metrological perspective, the method developed is based on dynamic load thermomechanical analysis (DL TMA) principles while accepting that subjected to measurements of sample in the form of a physical substrate/PVD coating model corresponds to the sample of a material with viscoelastic properties. The possibilities of using the DL TMA for investigating thermomechanical properties of such systems are also described in [29-32]. The feature that makes the method developed distinct is that monitoring of internal stress changes in the coating is based on measurements of temperature and linear shifts of the substrate during annealing by developed curve.

\section{Experimental}

Three types of substrate/CrN/CrCN gradient coating systems were selected for the purpose of diagnostic tests, with a total coating thickness of $8.2 \mu \mathrm{m}$. The coatings were deposited on a substrate of molybdenum, which was mechanically polished to the roughness of ca. $\mathrm{Ra} \sim 0.05 \mu \mathrm{m}$. The substrates were made in the shape of a cylinder with the diameter of $3 \mathrm{~mm}$ and the length of $30 \mathrm{~mm}$. The first of a two-layered $\mathrm{CrN} / \mathrm{CrCN}$ coating was analyzed with no transitional layer between chromium nitride and chromium carbon nitride (Fig. 1, type 1).

The deposition process of the $\mathrm{CrN}$ layer was conducted with the substrate polarization voltage of $70 \mathrm{~V}$ and with the arc current of $80 \mathrm{~A}$ in a nitride atmosphere under the pressure of $1.8 \mathrm{~Pa}$. In order to obtain the $\mathrm{CrCN}$ layer, acetylene was introduced into the chamber $(10 \mathrm{sccm})$ $[33,34]$. This made it possible to obtain a discrete percentage change of the carbon content in the layer.

The second and third coating tested (Fig. 1, type 2 and type 3 ) were two-layered $\mathrm{CrN} / \mathrm{CrCN}$ gradient coatings with a transition layer between chromium nitride and chromium carbon nitride $(\mathrm{CrN}-\mathrm{CrCN})$. The $\mathrm{CrN}$ coating was deposited with the same technological parameters as in the case of the first coating. In order to obtain a transition layer between the $\mathrm{CrN}$ and $\mathrm{CrCN}$ layers, the flow rate was altered by $2 \mathrm{sccm}$ every $2 \mathrm{~min}$ in five stages. This resulted in a change to the carbon concentration in the transition layer from 0 to 10 at.\% [33, 34]. In this manner, a monotonic change was obtained of the physico-chemical parameters between the $\mathrm{CrN} / \mathrm{CrCN}$ layers (Fig. 1). The experimental tests were conducted with the use of a compensation dilatometer constructed by the authors, in the conditions of temperature modulation and phase-sensitive registration of thermal and dilatometric responses. The technical details of the method and the conditions of the measurement of the temperature and linear displacement of the systems under examination were described in detail in the studies [1-4]. For the purpose of a research on the impact of long-lasting thermal and mechanical loads on the stability of the systems (substrate $\mathrm{Mo} / \mathrm{CrN} / \mathrm{CrCN}$ coating) designed a specific test curve (diagnostic curve) (Fig. 2).

It was assumed that in the phases $\mathrm{A}, \mathrm{C}$ and $\mathrm{E}$ of the curve (Fig. 2), the temperature will change linearly at a rate of $q=5^{\circ} \mathrm{C} \mathrm{min}{ }^{-1}$. In phases $\mathrm{B}$ and $\mathrm{D}$, respectively, at 200 and $290^{\circ} \mathrm{C}$, isothermal annealing was adopted, where additionally a sinusoidal modulation of the temperature with amplitude $A_{\mathrm{Ts}}=10{ }^{\circ} \mathrm{C}$ and period $p=7 \mathrm{~min}$ was used. Modulation parameters were subjected to experimental optimization. In optimization of modulation parameters, factors connected with construction of the

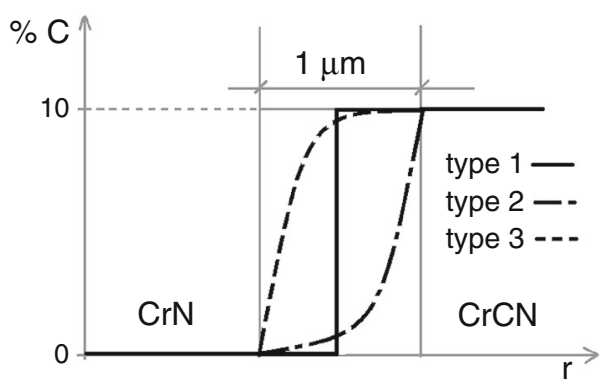

Fig. 1 Variation in carbon concentration in the transition layer 
Fig. 2 Diagnostic curve

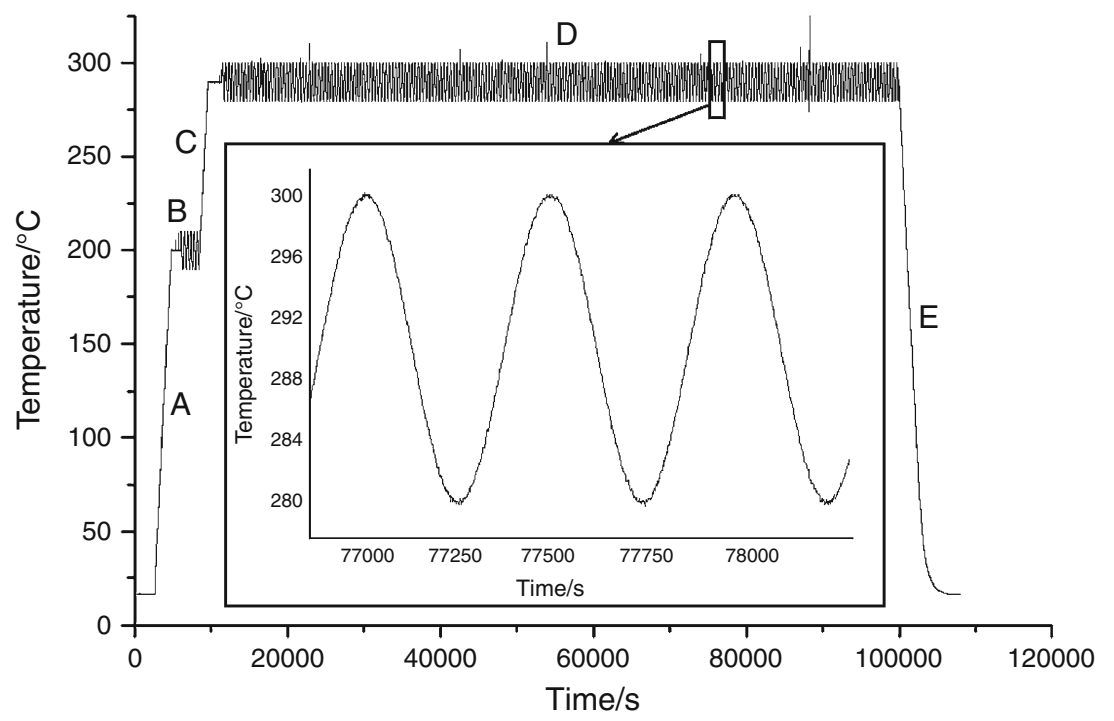

measuring apparatus and physical properties of the structural elements of the system (substrate/coating), including heat conductivity and heat capacity, were taken into account.

The results of measurements of the amplitudes of the cyclical temperature changes of the tested system $\left\langle A_{\mathrm{T}}>\right.$ and extensions $<A_{\mathrm{L}}>$, carried out in accordance with the phase $\mathrm{B}$ of curve, were used in the determination of the equivalent thermal expansion coefficient of the system according to the following formula:

$\alpha_{\mathrm{AC}}=\frac{1}{L_{\mathrm{oT}}} \cdot\left(\frac{\left\langle A_{\mathrm{L}}\right\rangle}{\left\langle A_{\mathrm{T}}\right\rangle}\right)$

where $L_{o T}$ is the initial length of the substrate of the system in measurement temperature $T,\left\langle A_{\mathrm{T}}\right\rangle$ is the average amplitude of the cyclic changes to the substrate temperature and $\left\langle A_{\mathrm{L}}>\right.$ is the average amplitude of the changes to the substrate displacements [1-4]. By making measurements of the values of the indices for the substrate without the coating-deposited $\alpha_{\mathrm{AC}}^{\mathrm{s}}$ and for the substrate with a coating-deposited $\alpha_{A C}^{1}$, one can determine the relative increment of the $\alpha_{\mathrm{AC}}$ ratio. This constitutes a quantitative measure of the thermomechanical load of the substrate in the temperature of the measurement $\left(200{ }^{\circ} \mathrm{C}\right)$ :

$\Delta \alpha_{\mathrm{AC}}^{\%}=\frac{\alpha_{\mathrm{AC}}^{\mathrm{s}}-\alpha_{\mathrm{AC}}^{1}}{\alpha_{\mathrm{AC}}^{\mathrm{s}}} \cdot 100 \%$

On the other hand, the measurements carried out according to the D phase curve (Fig. 2) were used to record the value of the amplitude of dilatometric response of the system $<A_{\mathrm{L}}>$ and its changes in the function of time. The time of isothermal annealing in the temperature of $290{ }^{\circ} \mathrm{C}$ was $1500 \mathrm{~min}$. During annealing, the samples were in the atmosphere of laminarily flowing argon.

\section{Computer model}

For the systems analyzed for the substrate/gradient coating (Fig. 1), a mathematical and computer model was created to describe the state of internal thermal stresses and strains after the PVD deposition processes. The diagram of the systems modeled including a discretization mesh is presented in Fig. 3.

For the type 1 system (without a gradient layer between $\mathrm{CrN}$ and $\mathrm{CrCN}$ ), the thicknesses of the $\mathrm{CrN}$ and $\mathrm{CrCN}$ layers are $4 \mu \mathrm{m}$ each, and the thickness of the $\mathrm{Cr}$ layer is $0.2 \mu \mathrm{m}$. The cylindrical core of the molybdenum substrate accepted for the calculations possesses the height of $250 \mu \mathrm{m}$ and the radius of $150 \mu \mathrm{m}$. For the systems types 2 and 3 (with a gradient layer between $\mathrm{CrN}$ and $\mathrm{CrCN}$ ), the thicknesses of the $\mathrm{CrN}$ and $\mathrm{CrCN}$ layers are $3.5 \mu \mathrm{m}$ each, the thickness of the gradient layer is $1 \mu \mathrm{m}$ and the thickness of the Cr layer is $0.2 \mu \mathrm{m}$. The core is identical as in the case of the type 1 system. The physical and mathematical model that makes it possible to determine the internal thermal stresses was developed based on the [18-24] and classical theory of elastic-plastic materials [25]. The details of the design of the computer model used based on an FEM analysis are contained in the studies $[13,26]$ and in the documentation of the Comsol package, with the aid of which the calculations were made. The material constants that were used in the simulation are found in Table 1.

For the mathematical description of the gradient layer between $\mathrm{CrN}$ and $\mathrm{CrCN}$, the following transition functions were used: the step function (type 1 system), the parabolic function (type 2 system) and the root function (type 3 system). The details of the mathematical structure of these functions for the description of physico-chemical 
Fig. 3 Diagram of the object including mesh

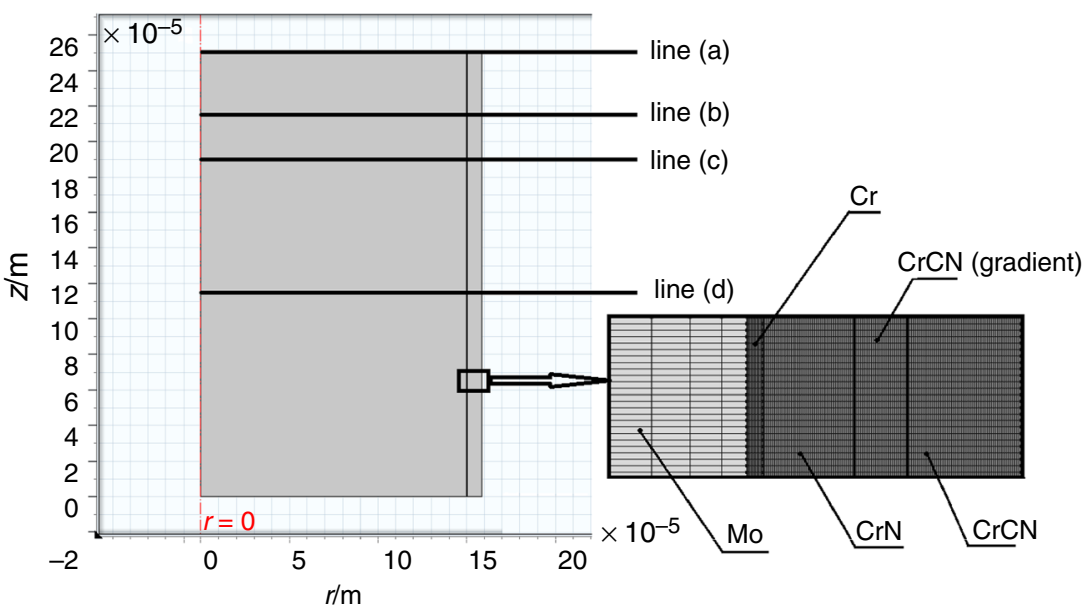

Table 1 Material constants used for simulation

\begin{tabular}{llll}
\hline Material & $\begin{array}{l}\text { Young's } \\
\text { modulus } / \mathrm{GPa}\end{array}$ & $\begin{array}{l}\text { Thermal expansion } \\
\text { coefficient } / 1 /{ }^{\circ} \mathrm{C}\end{array}$ & $\begin{array}{l}\text { Poisson's } \\
\text { ratio/- }\end{array}$ \\
\hline $\mathrm{Mo}$ & 329 & $4.9 \times 10^{-6}$ & 0.31 \\
$\mathrm{Cr}$ & 280 & $6.2 \times 10^{-6}$ & 0.21 \\
$\mathrm{CrN}$ & 330 & $2.3 \times 10^{-6}$ & 0.26 \\
$\mathrm{CrCN}$ & 380 & $2.6 \times 10^{-6}$ & 0.27 \\
\hline
\end{tabular}

parameters (e.g., the Young's modulus) are included in the studies [13-17]. The purpose of the simulations is to determine the state of thermal stresses for the systems after the PVD process.

\section{Results and discussion}

With the use of the computer model developed, for the systems under examination, the distributions of von Mises thermal stresses were determined (Figs. 4a, 5a, 6a); furthermore, the distributions of stresses along the axis of the sample were determined (Figs. $4 b, 5 b, 6 b$ ). In all distributions of stresses, the units are $\mathrm{Pa}$.

Considering the dimensional disproportions of the core in relation to the coating, the distributions of stresses (Figs. 4-6) present a fragment of the base of the sample, whereas the deformation of the coating including the core was magnified 20 times to increase the legibility. The calculation results illustrated in Figs. 4-6 show role of the coating in the development of stresses in the substrate. First of all, based on the calculated stress distribution as expected showing that the stresses within the layers of $\mathrm{CrN}$ and $\mathrm{CrCN}$ coatings are negative (compressive), and $\mathrm{Cr}$, and the substrate inside the positive (tensile) (Figs. 4b, 5b, 6b). This is connected with various values of the thermal expansion coefficients of the substrate and the coating layers. Stress distributions for the type 1 system with a step change in the concentration of carbon in the coating (Fig. 4) are characterized by a characteristic breaking of the isoline stress on the boundary layers of $\mathrm{CrN}$ and $\mathrm{CrCN}$ coatings, due to discontinuity of the first type of the transition function. From the physical point of view, this is a (a)

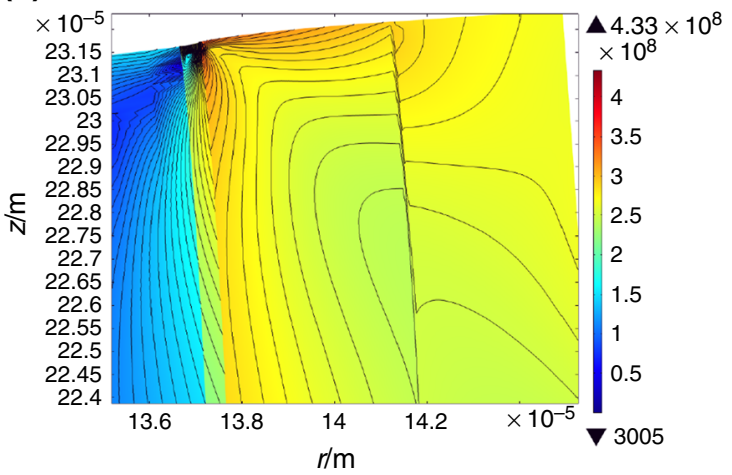

(b)

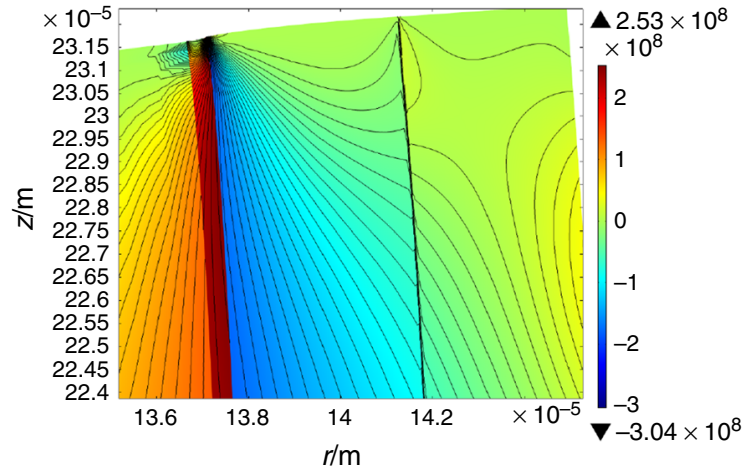

Fig. 4 Type 1 system: a distribution of von Mises stresses (Pa), b distribution of stresses along the sample (Pa) 
(a)

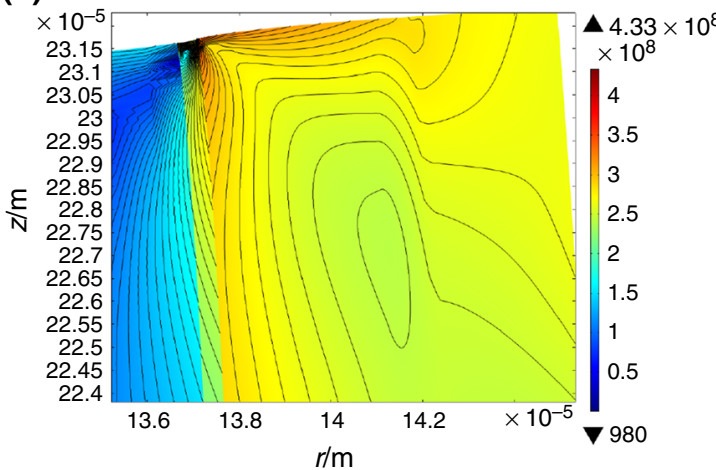

(b)

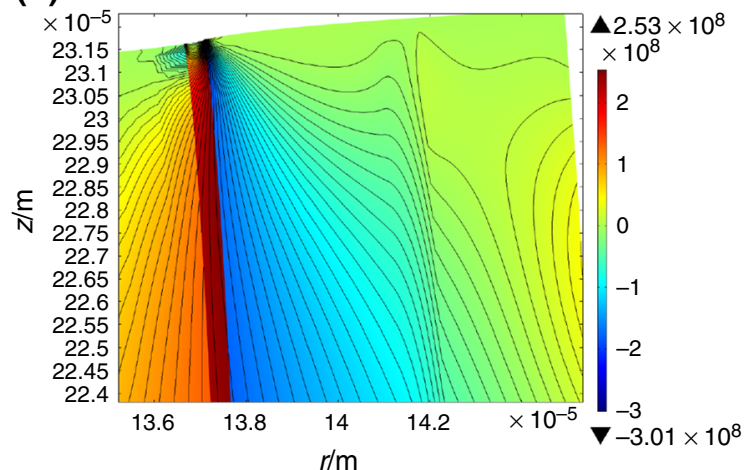

Fig. 5 Type 2 system: a distribution of von Mises stresses $(\mathrm{Pa}), \mathbf{b}$ distribution of stresses along the sample $(\mathrm{Pa})$

(a)

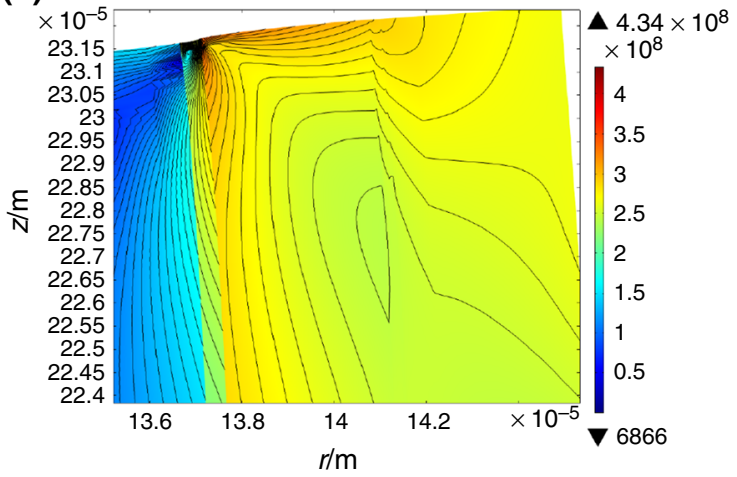

(b)

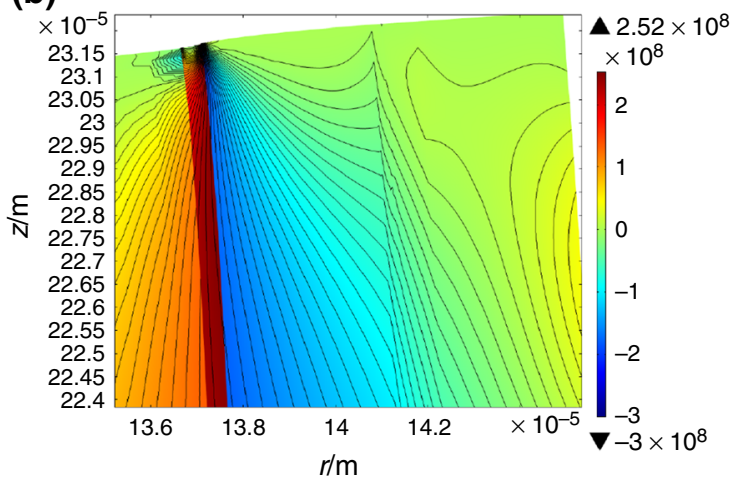

Fig. 6 Type 3 system: a distribution of von Mises stresses $(\mathrm{Pa}), \mathbf{b}$ distribution of stresses along the sample (Pa)

boundary between two different materials. The effect of the breaking of the stress isolines does not occur in the systems of types 2 and 3 (Figs. 5, 6) due to the continuous change of the physico-chemical parameters between $\mathrm{CrN}$ and $\mathrm{CrCN}$. In addition, the absence of the transition layer (type 1 system) or in the case of its presence (system 2 and 3), type of shape changes in the carbon concentration results in different thermal state of internal stress mapped to different shape of the isoline stress and their mutual arrangement. The differences between the maximum and minimum stress for all tested systems had almost the same values. Listing results of the simulation document the important role of PVD coatings in the test case of the $\mathrm{CrN}$ coating/ $\mathrm{CrCN}$ coatings, in the development of stress in the substrate. The following experimental results conducted by means of the method developed show that the magnitude variation in the stress is so large that as a result of selected thermomechanical loads, there is a measurable difference in the measured values of elongation of the substrate. Figure 7 presents an example collection of the measurements of changes to the amplitudes of elongations under the influence of sinusoidal temperature variations for two samples: a Mo substrate with a $\mathrm{CrN} / \mathrm{CrCN}$ gradient coating

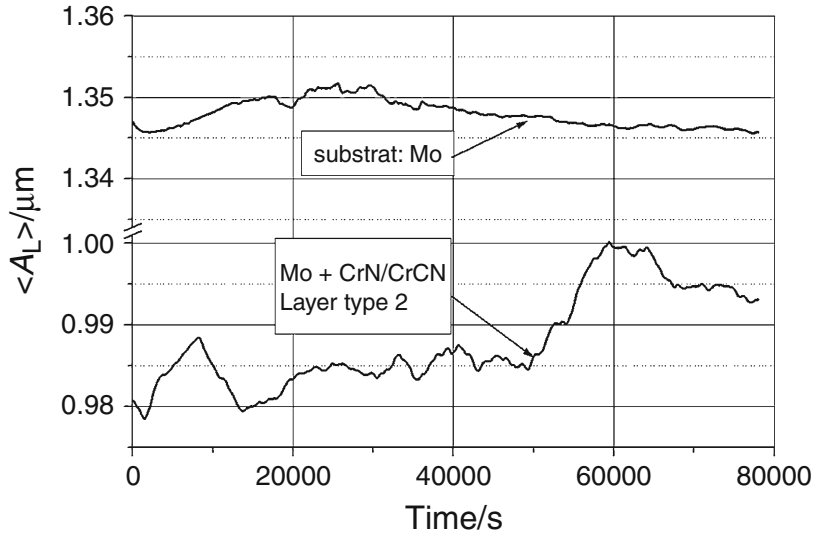

Fig. 7 Variations in the amplitudes $\left\langle A_{\mathrm{L}}>\right.$ of the Mo substrate with no coating and the Mo substrate with the type 2 gradient coating deposited in the function of the annealation time in the temperature of $290{ }^{\circ} \mathrm{C}$

(type 2 system) and a Mo substrate without any coating deposited. The results presented illustrate the influence of the type of the coating deposited on the thermomechanical load of the substrate and on the thermal stability of the 


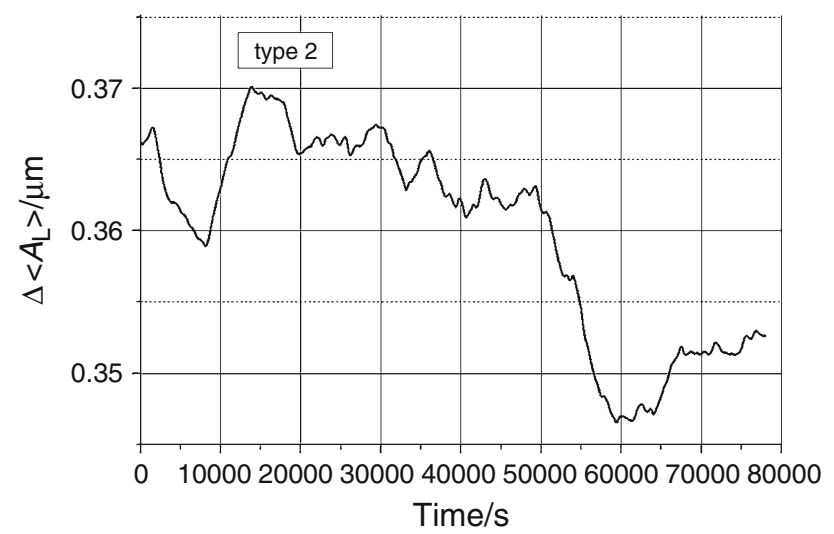

Fig. 8 Time course of the values of the difference of amplitudes $<A_{\mathrm{L}}>$ for the substrate with no coating and the substrate with the type 2 gradient coating

system during long-lasting annealation in the temperature of $290{ }^{\circ} \mathrm{C}$.

Regardless, these results are presented in the form of the amplitude difference $\Delta<A_{\mathrm{L}}>$ (Fig. 8) measured for the substrate with coating and the substrate without coating.

For the purpose of an analysis of the influence of the gradient coating type on the state of substrate elongations, Fig. 9 contains the course of the $\Delta<A_{\mathrm{L}}>$ values for the systems under examination.

The results document the existence of the effect of a particular shape changes in the concentration of carbon in the boundary layer $\mathrm{CrCN}$ coatings on the reaction system (substrate/coating) on thermomechanical interaction between the substrate and the coating deposited as a function of annealing time at $290{ }^{\circ} \mathrm{C}$. The results explicitly document the existence of a substantial influence of the type of the structure used for the gradient coating on the conditions of thermomechanical interactions between the substrate and the coating deposited in the function of the time of annealation in the temperature of $290{ }^{\circ} \mathrm{C}$. It is evident from an analysis of the courses of the curves and mutual positions that considering the adhesion quality of the coating to the substrate, the system with the type 2 coating is the most advantageous system in the measurement conditions applied. There also occurs a quantitative correlation between the courses of change of equivalent thermal expansion coefficients $\Delta \alpha_{\mathrm{AC}}$ registered in the annealation time and type of the system (Fig. 10).

Based on Fig. 10, one can explicitly state that an increase in the value of a change to $\alpha_{\mathrm{AC}}$ leads to an increased difference between the elongation of the Mo substrate itself in relation to the substrate of the system with a deposited coating.

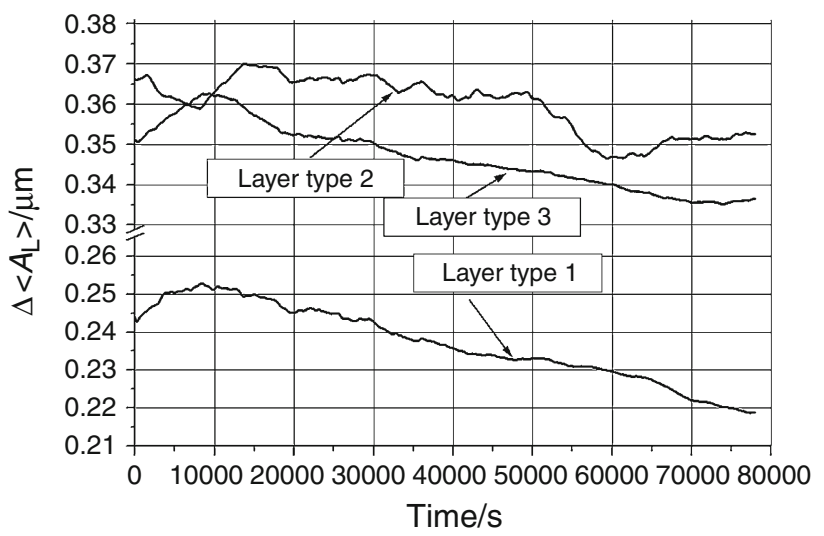

Fig. 9 Courses of $\Delta<A_{\mathrm{L}}>$ values for the systems under examination of types 1,2 and 3

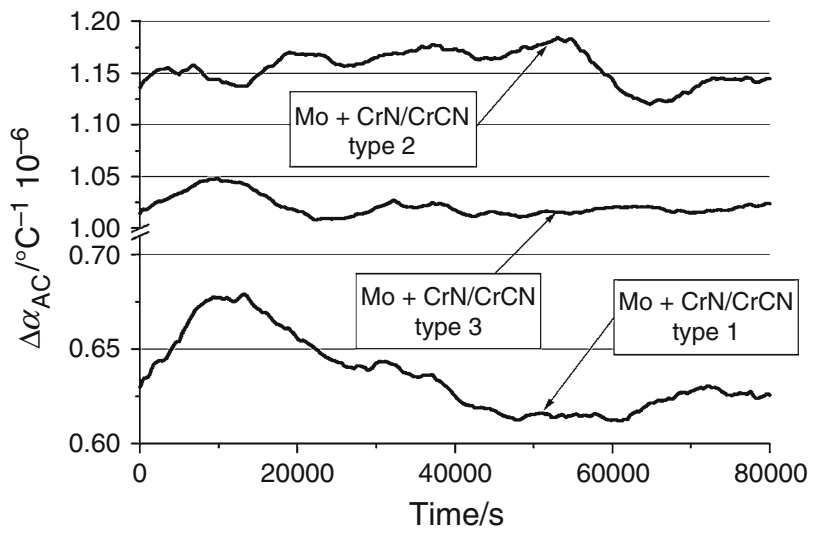

Fig. 10 Collection of the measurement results of the changes in the value of equivalent thermal expansion coefficient $\Delta \alpha_{\mathrm{AC}}$ for systems of types 1,2 and 3

\section{Conclusions}

1. It was demonstrated that the method developed for the diagnostics of substrate/gradient coating systems based on DL TMA allows a quantitative determination of the influence of the gradient layer form on the total elongation of the substrate of the system. Hence, an assessment of change of the state of thermal stresses in the whole system is possible.

2. The diagnostic method proposed also facilitates an assessment of a change to the thermomechanical properties of the gradient coatings deposited by an examination of the change to the value of the $\alpha_{\mathrm{AC}}$ index in the function of temperature. Those systems where the value of this index does not significantly change as a result of annealation processes are characterized by a high thermal stability, and they exhibit a high adhesion of the coating to the substrate. 
Acknowledgements This research was co-funded by the National Science Centre, as part of the UMO-2011/03/N/ST8/04104 research grant.

Open Access This article is distributed under the terms of the Creative Commons Attribution License which permits any use, distribution, and reproduction in any medium, provided the original author(s) and the source are credited.

\section{References}

1. Myśliński P, Kamasa P, Wąsik A. Application of temperature modulated relative dilatometry. Temperatures of adhesion degradation. J Therm Anal Calorim. 2001;65:553-9.

2. Myśliński P, Precht W, Kukiełka L, Kamasa P, Pietruszka K, Małek P. A possibility of application of MTDIL to the residual stresses analysis. J Therm Anal Calorim. 2004;77:253-8.

3. Myśliński P, Kamasa P, Gilewicz A, Staśkiewicz J. Detection of mechanical effects of adhesive thin films on substrate using the modulated-temperature dilatometry (MT DIL). J Therm Anal Calorim. 2007;88:737-40.

4. Myśliński P. Investigation of the thermal stability of hard coatings by modulated temperature dilatometry. Vacuum. 2009;83:757-60.

5. Fitz C, Kolitsch A, Fukarek W. Stress relaxation during annealing of boron nitride films. Thin Solid Films. 2001;389:173-9.

6. Fitz C, Fukarek W, Koltisch A, Moller W. An instrument for in situ stress measurement in thin films during growth. Surf Coat Technol. 2000;128-129:474-8.

7. Raveh A, Zukerman I, Shneck R, Avni R, Fried I. Thermal stability of nanostructured superhard coatings: a review. Surf Coat Technol. 2007;201:6136-42.

8. Bielawski M, Seo D. Residual stress development in UMS TiN coatings. Surf Coat Technol. 2005;200:1476-82.

9. Hultman L, Engström C, Birch J, Johansson MP, Oden M. Review of the thermal and mechanical stability of TiN-based thin films. Zeitschrift für Metallkunde. 1999;90:803-13.

10. Mitterer C, Mayrhofer PH, Musil J. Thermal stability of PVD hard coatings. Vacuum. 2003;71:279-84.

11. Hultman L. Thermal stability of nitride thin films. Vacuum. 2000;57:1-30.

12. Zeng XT, Zhang S, Sun CQ, Liu YC. Nanometric-layered CrN/ TiN thin films: mechanical strength and thermal stability. Thin Solid Films. 2003;424:99-102.

13. Ratajski J, Szparaga Ł. On transition functions and nonlinearity measures in gradient coatings. J Achiev Mater Manuf Eng. 2012;54(1):83-92.

14. Qianjun X, Shouwen Y, Yilan K. Residual stress analysis of functionally gradient materials. Mech Res Commun. 1999; 26:55-60.

15. Zhang H-C, Tan W, Li Y-D. Effect of the transitional gradient of material property on the mechanical behavior of a non-homogeneous interlayer. Comput Mater Sci. 2008;42:122-9.

16. Li YD, Zhang HC, Tan W. Fracture analysis of functionally gradient weak/micro-discontinuous interface with finite element method. Comput Mater Sci. 2006;38:454-8.
17. Szparaga $Ł$, Ratajski J, Bartosik P. Strain field analysis in nanoindentation test of gradient coatings. Arch Mater Sci Eng. 2013;64(2):219-27.

18. Śliwa A, Mikuła J, Dobrzański LA. FEM application for modelling of PVD coatings properties. J Achiev Mater Manuf Eng. 2010;41(1-2):164-71.

19. Śliwa A, Dobrzański LA, Kwaśny W, Staszuk M. Simulation of the microhardness and internal stresses measurement of PVD coatings by use of FEM. Arch Comput Mater Sci Surf Eng. 2010;2(4):213-20.

20. Dobrzański LA, Śliwa A, Kwaśny W. Employment of the finite element method for determining stresses in coatings obtained on high-speed steel with the PVD process. J Mater Process Technol. 2005;164-165:1192-6.

21. Haider J, Rahman M, Corcoran B, Hashmi MSJ. Simulation of thermal stress in magnetron sputtered thin coating by finite element analysis. J Mater Process Technol. 2005;168:36-41.

22. Wiklund U, Gunnars J, Hogmark S. Evaluation of new multilayered physical vapour deposition coatings in sliding contact. Wear. 1999;236:88-95.

23. Pauleau Y. Generation and evolution of residual stresses in physical vapour-deposited thin films. Vacuum. 2001;61(2-4):175-81.

24. Carvalho NJM, Zoestbergen E, Kooi BJ, De Hosson JTM. Stress analysis and microstructure of PVD monolayer TiN and multilayer TiN/(Ti, Al)N coatings. Thin Solid Films. 2003;429:179-89.

25. Johnson KL. Contact mechanics. Cambridge: Cambridge University Press; 1985.

26. Szparaga Ł, Ratajski J, Zarychta A. Multi objective optimization of wear resistant TiAlN and TiN coatings deposit by PVD techniques. Arch Mater Sci Eng. 2011;48(1):33-9.

27. Szparaga $Ł$, Ratajski J. Pareto optimal multi-objective optimization of antiwear TiAlN/TiN/Cr coatings. Adv Mater Sci. 2014;14(1):5-13.

28. Lakkaraju RK, Bobaru F, Rohde SL. Optimization of multilayer wear-resistant thin films using finite element analysis on stiff and compliant substrates. J Vac Sci Technol A. 2006;24:146-55.

29. Rice MA. Dynamic mechanical response of plasticizer-laden acoustic polyurethanes extrapolated to higher frequencies using time-temperature superposition technique. J Therm Anal Calorim. 2014;118:377-96.

30. Podgórski M. Thermo-mechanical behavior and specific volume of highly crosslinked networks based on glycerol dimethacrylate and its derivatives. J Therm Anal Calorim. 2013;111:1235-42.

31. Malucelli G, Alongi J, Gioffredi E, Lazzari M. Thermal, reeological, and barrier properties of waterborne acrylic nanocomposite coatings based on boehmite or organo-modified montmorillonite. J Therm Anal Calorim. 2013;111:1303-10.

32. Wang F, Guo GP, Ma QY, Gu MF, Wu XY, Sheng S, Wang X. Investigation on the thermo-mechanical properties and thermal stability of polylactic acid tissue engineering scaffold material. J Therm Anal Calorim. 2013;113:1113-21.

33. Warcholiński B, Gilewicz A, Ratajski J. $\mathrm{Cr}_{2} \mathrm{~N} / \mathrm{CrN}$ multilayer coatings for wood machining tools. Tribol Int. 2011;44:1076-82.

34. Warcholiński B, Gilewicz A. Effect of substrate bias voltage on the properties of $\mathrm{CrCN}$ and $\mathrm{CrN}$ coatings deposited by cathodic arc evaporation. Vac. 2013;90:145-50. 